\title{
Els àngels músics, testimoni de la vida musical del Castelló del segle XV Oriol Casadevall
}

Aquest article no pretén ser un estudi musicològic d'organologia medieval, ni un pamflet propagandístic de les virtuts de la música antiga o, com s'acostuma a anomenar, històricament informada. Només vol ser una aproximació, a través de la iconografia, a l'ambient musical de la vila de Castelló d'Empúries en un moment precís de la seva història, l'Edat Mitjana, i sobretot, del segle XV.

Els intèrprets de música històrica, i en aquest cas concret, de música medieval, disposem de sis fonts de coneixement per a la interpretació de repertoris dels quals, aparentment, no en queda rastre a la nostra tradició cultural i que han estat desapareguts durant centenars d'anys.

En aquest escrit em centraré en una d'aquestes fonts, però a tall d'introducció m'agradaria fer una mica de repàs a les altres.

\section{Les fonts disponibles per estudiar la música medieval}

És impossible intentar fer un retrat de la música medieval de Castelló basant-nos només en informacions pròpies del municipi o el comtat perquè no comptem amb música escrita en aquesta zona en aquella època. I aquesta és, segurament, la primera font que hauríem de buscar per a la interpretació històrica musical. Quan ens referim a música escrita, hem de tenir en compte que parlem d'una part de la música que s'interpretava a l'Edat Mitjana i no de la música culta, que és la que ens acostuma a arribar per escrit.

De la música popular, aquella que no ha quedat recollida en els còdexs, no en tenim prou coneixements per poder saber exactament com era, com sonava i com s'interpretava. Hem de pensar que en aquell moment només es recollia per escrit allò que es considerava prou important per ser conservat. Molts dels còdexs que han arribat fins als nostres dies no són objectes útils, sinó objectes de luxe, perquè la majoria de la música era transmesa oralment (o mitjançant altres suports que no han perdurat), i interpretada de memòria (Busse Berger 2008). D'altra banda, no podem pensar que la partitura és un fidel reflex del resultat sonor final. Tot i que no és el període que ens ocupa, en el Renaixement tenim constància de la pràctica de l'ornamentació i la disminució malgrat que no apareguin reflectides en la música escrita, aspectes que modifiquen d'una manera molt important el que finalment escoltem. No tenim motius per pensar que a l'època medieval això no es produiia, ja que també tenim indicis d'aquesta pràctica (com ho demostra el còdex Faenza).

Un altre aspecte a tenir en compte és que la partitura és una font d'informació més enllà de la música que conté; el document físic en si ja 
El Còdex Faenza (Faenza, Biblioteca Comunale 117) és un manuscrit copiat en el centre o nord d'Itàlia a inicis del S. XV. La seva importància rau en el fet que es tracta del primer manuscrit dedicat completament a la música instrumental. Conté disminucions instrumentals a dues veus de peces seculars i litúrgiques de l'ars nova francès i italià.

aporta molta informació, sobretot pel que fa al context en el qual fou copiada.

Pel que fa a la música escrita, malauradament, no podem parlar d'un llegat musical de Castelló d'Empúries i hem d'ampliar la recerca a l'àmbit de la música medieval a Catalunya i, fins i tot, a la música medieval europea en general. El llegat musical conservat en el conjunt de la Corona d'Aragó és molt fragmentari i no ens ofereix un reflex complet de la música que s'interpretava en aquell moment. Malgrat això, cal tenir en compte que Barcelona esdevé, des de mitjan segle XIV, un dels referents musicals, sobretot durant el regnat de Joan l. Això ho sabem només gràcies a la documentació històrica que hi fa referència. Parlem de Barcelona perquè, des de mitjans del s. XIV, els comtes d'Empúries viuen, en gran mesura, a la cort barcelonina. Com veurem, tenim testimonis que corroboren l'accés de la cort emporitana a aquest repertori i ambient musical.

Malgrat la manca de fonts musicals escrites, que malauradament hem de fer extensiva a tota la música castellonina fins a inicis del s. XIX, tenim alguns indicis documentals que ens donen una idea de la vitalitat musical del Castelló medieval, tant pel que fa a la capella de cant de Sta. Maria de Castelló, com pel que fa a la música profana, vinculada a les festes populars i al casal comtal. Aquest context històric i social és una altra de les fonts de les quals els intèrprets de música medieval ens servim per obtenir informació.

Els historiadors castellonins Miquel Pujol i Canelles (1990) i Josep Maria Gironella (2013), entre d'altres, en el transcurs de les seves investigacions, han descobert un gran volum de documentació que fa referència a la vida musical de la vila. Un exemple el tenim en el cas del cavaller Bernat Seguí, estudiat per Gironella, que recluta a la vila una companyia de mercenaris per integrar-se a l'exèrcit cristià al servei del rei de Tremissèn on, a banda de cavallers i escuders, hi apareix un joglar d'Ordis anomenat Pere Carrera. Aquest fet, que vincula la música amb el món cavalleresc, no és excepcional, ja que Miquel Pujol ens parla d'un inventari de la Comanda del Temple de la vila del 1309, on hi podem trobar una rabeba $i$ algun instrument de percussió.

El gran volum de documentació vinculada amb la música correspon al període comprès entre la segona meitat del s. XIV i el s. XV. Gironella, per exemple, documenta una sèrie de pagaments efectuats pel dispenser comtal l'any 1370 a diferents músics vinculats a la família reial catalana i a d'altres monarquies de l'Occident europeu, que evidencien la voluntat del comte Joan I d'emular, en la mesura del possible, la cort reial. $\mathrm{O}$ la documentació que Miquel Pujol recull de la capella musical de Sta. Maria, dels seus beneficis, de l'escola de cant, o de les festes que se celebren a la

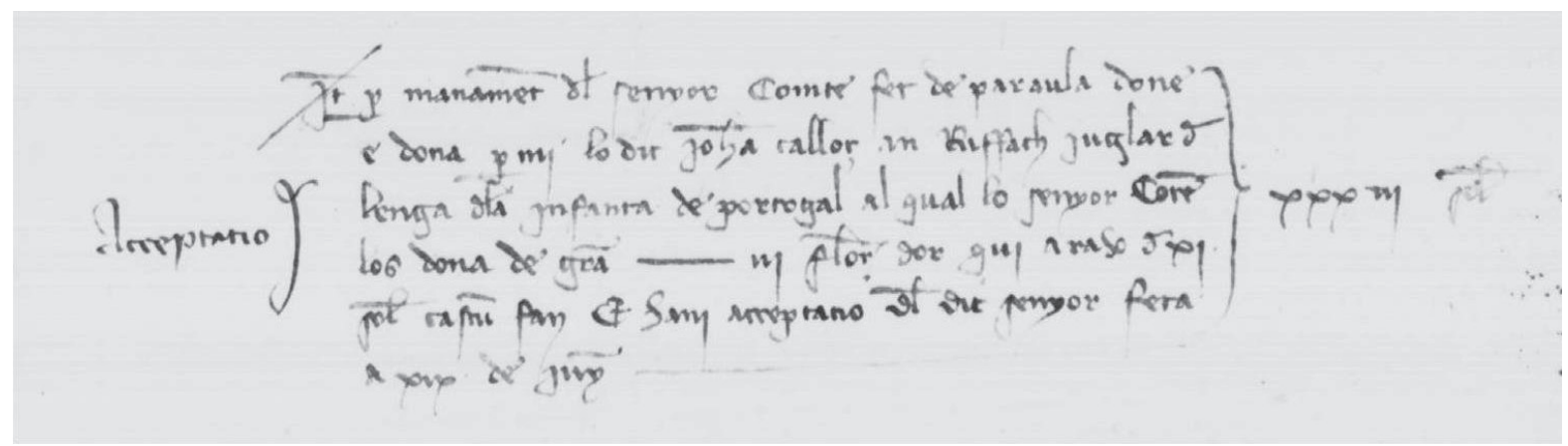

Pagament a Rifac, joglar de llengua de la infanta de Portugal (AMCE, Fons comtat d'Empúries. Fundació Casa Ducal de Medinaceli). 
vila, com la festa del Corpus, segurament una de les més esplendoroses i que més músics ocupava.

Per tancar l'apartat de les fonts escrites, només ens queda la tractadística musical. En aquest apartat podem diferenciar dues branques, la tractadística teòrica (compositiva) i la tractadística interpretativa o performativa. A nivell europeu s'ha conservat nombrosa tractadística compositiva $\mathrm{o}$ teòrica però no passa el mateix amb la performativa, ja que haurem d'esperar al Renaixement per trobar els primers tractats d'interpretació. En aquest sentit, només ens podem remetre a comentaris sobre la manera de tocar d'alguns intèrprets, especialment en la música trobadoresca, sovint amb la voluntat de criticar o ridiculitzar algun adversari, o en la lletra d'alguna peça, on s'aconsella sobre la manera de cantar:

\footnotetext{
Per gridar forte non si canta bene ma con soav'e dolce melodia si fa bel canto e ciò vuol maestria. «Ogelletto silvagio per stagione», madrigal canònic de Jacopo da Bologna (Florència, Biblioteca Medicea-Laurenziana, Palatino 87 Còdex Squarci-

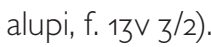

O en el text de Jaufré Rudel

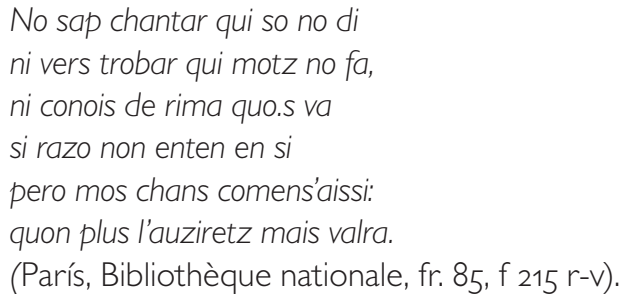

Malgrat no tenir físicament cap exemple de tractadística del municipi, Miquel Pujol (1984) esmenta un tractat poètic, el Doctrinal de trobar, que Ramon de Cornet dedica a l'infant Pere al 1324, un any abans de ser comte d'Empúries (1325-1341). En aquest sentit, Miquel Pujol també fa referència al castelloní Nicolau Gori que, al 1384, està en possessió de les Regles de trobar de Jofre de Foixà, entre d'altres obres. Recordem que a la corona d'Aragó la lírica d'arrel trobadoresca encara es manté ben viva fins ben entrat el s. XV.
Per suplir aquesta manca d'informació performativa, l'intèrpret de música medieval pot prendre referències de les tradicions folklòriques, tot i que els estudis etnomusicològics han demostrat que la tradició folklòrica és molt canviant, tant geogràficament com temporal, i per tant s'ha de ser curós a l'hora d'extreure'n informació per a la interpretació històrica i no fer-ne una adaptació sense filtres. Altres fonts similars són la investigació empírica dels propis intèrprets —és a dir, l'experimentació amb les possibilitats de l'instrument— i l'anàlisi de les gravacions discogràfiques, així com de les interpretacions que fan altres grups sobre el mateix repertori. Ambdues fonts ens possibiliten la presa de referències i un criteri que ens permeti prendre decisions a l'hora d'interpretar un repertori —el medieval- que ens ofereix un ampli ventall de possibilitats, precisament per la seva manca de sistematització, en comparació amb la música clàssica o d'altres estils.

He deixat per al final la font que és objecte d'aquest article, la iconografia musical, que és l'estudi de les imatges on apareixen escenes musicals. Aquestes imatges permeten, tant a musicòlegs com a intèrprets, extreure informació performativa i organològica; és a dir, sobre la interpretació i sobre els instruments. Poques són les restes físiques d'instruments d'època medieval que hagin sobreviscut fins als nostres dies. Aquesta és la principal font per a l'estudi dels instruments i per a la seva reconstrucció.

\section{La iconografia musical del Castelló d’Empú- ries medieval}

En aquest punt ens remetem ja a Castelló d'Empúries i a les seves fonts iconogràfiques d'època medieval, que són: un protocol notarial de finals del s. XIII i el retaule de la Verge de la Candelera, de la segona meitat del s. Xv. En ambdues fonts hi apareixen imatges de diferents personatges que interpreten música.

En un protocol notarial de Pere Serra, datat

1 Un protocol notarial és un conjunt d'instruments públics i d'altres documents que hi són incorporats, autoritzats per un mateix notari en el decurs d'un 


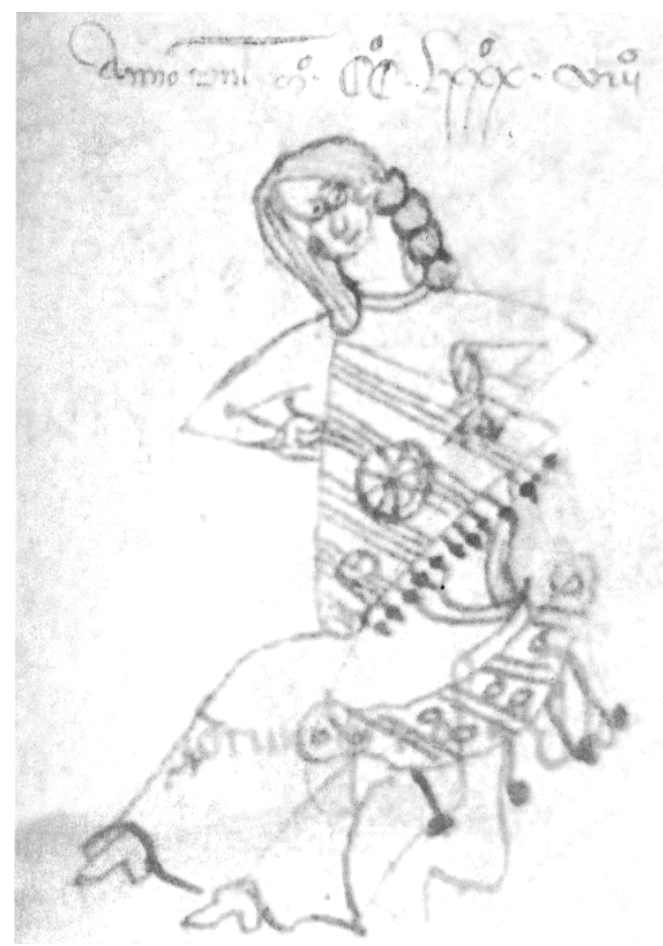

Dona tocant el saltiri triangular amb els plectres. Protocol notarial de Castelló d'Empúries (Arxiu Històric de Girona, Fons Castelló, 47).

al 1288, i conservat a l'Arxiu Històric de Girona, ens trobem amb la imatge de dues dones amb instruments. Una d'elles sosté un saltiri triangular sobre les cuixes i pinça les cordes de l'instrument mitjançant dos plectres, un a cada mà. A l'altra imatge hi trobem una dona amb un llaüt. Tot i que en aquest cas, per la posició de la mà closa sobre les cordes, no s'aprecia bé si utilitza el plectre; podríem deduir que sí que ho fa. En el mateix document on apareixen aquestes imatges, trobem també altres dibuixos (sanefes i mastins) i alguns exemples de lírica trobadoresca. ${ }^{2}$ Aquest fet ens permetria designar aquestes dues dones com a trobairitz o joglaresses. En cas de ser així,

any, i enquadernats en un o diversos volums. El fons notarial de Castelló d'Empúries, conservat a l'Arxiu Històric de Girona, data d'entre el 1260 i el 1799, i consta de $\mathbf{2 . 4 2 2}$ llibres. Per la seva antiguitat i pel seu volum, el podem considerar un dels fons notarials més importants de Catalunya i, per extensió d'Europa, ja que els fons notarials del Principat són dels més importants d'Europa.

2 Sobre aquest document hi està treballant Anna Radaelli, professora de la Universitat Sapienza de Roma, treball del qual ben segur aviat en tindrem novetats. aquesta iconografia seria una de les poques representacions conservades d'aquest estil. Un altre fet curiós és el tipus d'instruments escollits per a les representacions, perquè no són els més habituals per acompanyar el cant monòdic, propi de la lírica trobadoresca, sinó de la música polifònica. Hem de tenir present que, durant la redacció d'aquest protocol, el comte d'Empúries era Ponç Hug IV (1277-1313), que figura entre els nostres trobadors més destacats.

L'altra font d'iconografia musical d'època medieval que trobem a Castelló, i a la qual vull dedicar el gruix d'aquest escrit, són els àngels músics del retaule de la Verge de la Candelera, ubicat a la basílica de Sta. Maria.

Darrere l'enorme reixa de ferro forjat, dins del presbiteri, s'hi troba el retaule d'alabastre de Beuda d'estil gòtic flamíger renaixentista. Obra única a Catalunya i una de les millors mostres de l'escultura gòtica catalana de la segona mei-

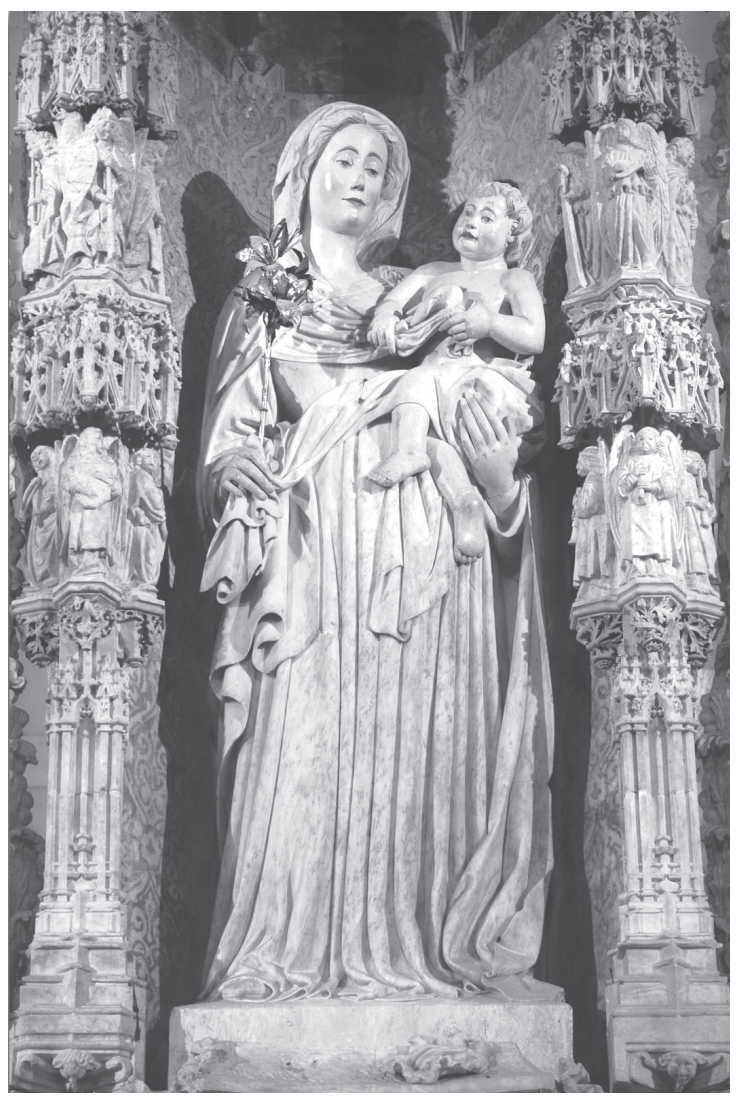

Fornícula del retaule de la Verge de la Candelera. Santa Maria de Castelló d'Empúries. 
tat del s. Xv; és, a més, el darrer retaule fet amb aquesta tècnica al nostre país.

Les primeres notícies que es tenen sobre l'execució del retaule daten del 18 de març de $1452 \mathrm{i}$, malgrat que hi treballaren molts mestres (com ara Vicenç Borràs), el nom que sobresurt és el del francès Ponç Gaspar (1456).

Constituit per un sòcol i un bancal, té una alçada total de 6,56 metres, tres dels quals corresponen a la fornícula de la Verge de la Candelera. El bancal es divideix en dos registres: l'inferior, on hi figuren deu relleus d'àngels que sostenen els escuts o símbols de les entitats promotores del retaule (per exemple, l'escut de Castelló d'Empúries; així com un pa, emblema de la institució benèfica del pa senyat); i el superior, amb quadres que representen escenes de la passió de Jesús.

Tot aquest parament serveix de peanya, on s'assenta la fornícula de la Verge Maria, de 1,40 metres d'amplària per 3 d'alçària. Als laterals hi trobem originàriament tres sèries sobreposades d'àngels músics ordenats en grups de tres —un total de divuit-, i cada grup està emmarcat per dosserets i peanyes. 3 Dins la fornícula hi trobem la majestuosa estàtua de la Verge de la Candelera, de 1,90 metres d'alçària, amb I'Infant recolzat sobre el braç esquerre i un motiu floral de metall a la mà dreta.

Malgrat que es considera que el retaule resta inacabat, ja que hi falten les dues ales que devien situar-se a ambdós costats de la fornícula, podem destacar tres etapes en la seva construcció. La primera, dedicada a la imatge de la Verge amb I'Infant; la segona, destinada als relleus escultòrics del bancal, i la darrera, destinada a la fornícula i al revestiment de la part posterior del conjunt.

La fornícula, que correspon a la tercera etapa de construcció del retaule, està executada per

3 Pujol (1984) parla de «...dos sèries sobreposades d'àngels músics ordenats en grups de tres —un total de dotze...». Sota el meu punt de vista, es tracta d'un error, ja que sobre aquestes dues sèries encara se n'entreveu una altra (de sèrie) d'àngels, a dreta i esquerra, igualment agrupats de tres en tres. Si es mira el retaule, a la part superior dreta, les tres figures han desaparegut totalment, mentre que a la part superior esquerra, s'entreveuen part dels cossos dels àngels músics, tot i que no prou com per endevinar quin instrument sostenen.
Vicenç Borràs, establert a Castelló, on exercia de magister domorun (constructor de cases), una titulació prou àmplia i que no equivaldria al paleta actual. Segons els experts, aquesta seria una part escultòricament més pobra, i podríem denominar el seu estil com a «art de tradició local».

Prenent com a referència els estudis realitzats per Jordi Ballester sobre iconografia musical de l'Edat Mitjana i Renaixement a casa nostra, l'escena musical predominant a la pintura catalana del moment és precisament la representació d'àngels músics. Hem de pensar que a nivell escultòric també és així. Ballester estableix uns percentatges en funció de la presència major o menor de determinades escenes: els àngels músics apareixen en un $45 \%$ del total; els soldats, heralds i ministrers, en un 34,5\%; els pastors músics, en un 10\%; i ja a més distància, altres personatges com santa Cecília o el rei David, que també s'acostumen a representar amb atributs musicals.

Dins de les escenes amb àngels músics, la de Castelló s'inclouria en les representacions amb la Mare de Déu i el Nen, on un grup d'àngels músics canten i toquen instruments, tant de corda com de vent. Podem trobar diferents grups instrumentals; hi ha qui intenta fer una ordenació entre grups de trompetes naturals o corns -instruments representatius - i instruments 0 conjunts musicals més diversos relacionats amb la pràctica musical. En el cas de Castelló, ens trobem amb un d'aquests conjunts més variats, amb instruments que a priori formarien part de diferents espais o repertoris musicals.

Aquest model iconogràfic és molt conegut en el gòtic fet en els territoris de la corona catalanoaragonesa, com per exemple, les representacions de la Verge i el Nen que trobem al retaule de la catedral de Tortosa, de Pere Serra (finals del s. XIV); al retaule del monestir de Sant Cugat, també de Pere Serra (finals del s. XIV); al retaule procedent de Vallmoll (Alt Camp) de Jaume Huguet (mitjan s. Xv); o al retaule procedent de Longares, d'Eric Estencop (segona meitat del s. XIV). Tots ells tenen la mateixa escena, encara que pintada i no esculpida. El que sí que diferencia el retaule de Castelló és el nombre d'àngels músics que hi figuren i la varietat d'instruments que hi 
són representats. En aquest cas, el conjunt instrumental que apareix representat al retaule castelloní és més semblant al que trobem en el retaule de Sta. Maria la Real de Nàjera, de Hans Mamling (1489), actualment al Museu Reial de Belles Arts d'Anvers. No en va foren creats a la mateixa època.

No hem de perdre de vista que l'escena no deixa de ser una visió al|legòrica d'un cor celestial que lloa la Verge i el Nen. Crec que no podem pensar que es tracta d'un conjunt instrumental real de l'època, una mena «d'orquestra medieval», però sí que seria plausible pensar que tots els instruments eren coneguts al Castelló del segle $\mathrm{XV}$, de manera que intentarem posar cada instrument en el seu context musical.

És important tenir en compte dos factors, com molt bé exposa Rosario Álvarez quan parla de la representació d'instruments en còdexs medievals. Al seu article (Álvarez Martínez 2007) explica com n'és d'important tenir en compte la funció de les imatges i els procediments de treball del miniaturista que copia de fonts anteriors, ja que pot comportar una «migració de models iconogràfics». Això succeeix quan el model copiat no té relació amb l'instrumentari de la zona perquè el model procedeix d'una altra regió. Crec que aquest no és el cas de la majoria dels instruments que apareixen en el retaule de Castelló: disposem de molta documentació que descriu amb detall la utilització de molts d'aquests instruments a les celebracions i festivitats de la vila. També és cert que n'hi ha d'altres que són més difícils de rastrejar (com la viola de roda), que podrien estar més relacionats amb la música popular, de la qual en queda poca constància documental, tant en els còdexs musicals com en la documentació històrica.

\section{Els instruments dels àngels del retaule de Castelló}

Tot seguit descriuré les imatges que ens ocupen, seguint les agrupacions de tres àngels, de dalt a baix i d'esquerra a dreta. Així doncs, en primer lloc ens trobem amb el primer grup d'imatges, de les quals només se'n conserva una part dels cossos dels àngels situats a l'esquerra, i sobretot al centre del grup, però no suficient com per poder veure quin instrument sostenen.

En el grup central del costat esquerre de la imatge hi trobem una trompeta natural, una trompeta recta i un tambor de cordes, dos instruments de vent metall i un de percussió. L'anafil o trompeta recta, en el centre del grup, és un instrument possiblement introduiit a Europa pels exèrcits sarraïns. En principi, és un instrument funcional, utilitzat en fanfares i tocs militars música heràldica i representativa. He dit «en principi» perquè Miquel Pujol recull la següent cita d'un docu-

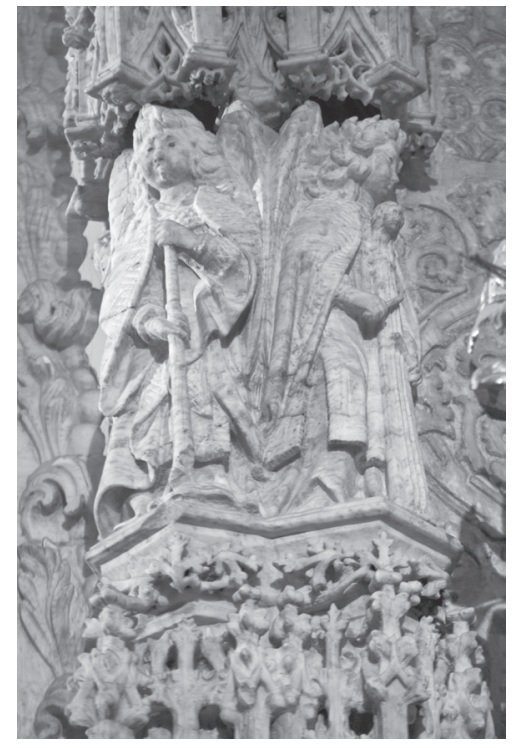

Anafil i tambor de cordes. Retaule de la Verge de la Candelera de Sta. Maria de Castelló d'Empúries (foto: Manel Puig). ment datat al 18 de febrer del 1415 durant les celebracions fetes per la gran conversió dels jueus de la vila: «Una vegada celebrat el convit, es traslladaren a la plaça dels Homes, on nombrosos músics amb llurs instruments, entre els quals no mancaven els anafils, tocaren danses i ballades variades» (Pujol Canelles 1990: 13). Per tant, trobem documentat aquest instrument en un context ben diferent a l'habitual i que, per les seves característiques organològiques, ens sorprèn trobar-lo en un context de danses, ja que a banda del llavi no disposa de cap mecanisme per interpretar les notes i té un paper més aviat melòdic.

Aquest instrument, a causa de les seves prestacions limitades, poc a poc anirà essent substituït per d'altres, com el que l'acompanya en aquest grup d'àngels: una trompeta natural o una tromba da tirarsi. Entre els s. XIV i XV, aquesta trompeta recta comença a doblar el tub, primer en forma d'essa i des- 
prés sobre si mateix. En aquest cas, la diferència entre la trompeta natural i la tromba da tirarsi és que aquesta té una part lliscant entre el tudell i la corba de l'instrument, que permet modificar la llargada i, per tant, el so, mentre que la trompeta natural té un cos uniforme. En el cas que ens ocupa, no tenim prou detalls per poder discernir si es tracta d'un o altre instrument.

La família del vent metall és molt present a la documentació conservada, fins al punt que Miquel Pujol apunta que els conceptes joglar i tocador de tuba apareixen com a sinònims. ${ }^{4}$ El 1451, un tal Aguiló cobra 11 sous per tocar la trompa als jochs dels salvatges; «grandi sono tubbarum et tamborinarum» a la batalla a ultrança que tingué lloc a Castelló d'Empúries entre dos cavallers el 1468 (Pujol Canelles, 1990); o els exemples descoberts per Josep Maria Gironella (2013) on consta que, al 1370, el dispenser del comte Joan I paga els serveis de quatre trompadors del rei de Portugal, com també de Mateu Almogàver, trompeta del rei de Sicília, i de Gauet, trompeta del rei d'Aragó. Fins i tot coneixem el nom de dos trompeters de Castelló, Vidal Xapus i Francesc d'Espolla.

El tercer instrument d'aquest grup podria semblar que es tracta d'una tromba (o trompeta) marina, però si ens fixem detingudament en la imatge podem observar que consta de tres cordes (a diferència de les trombes marines que en tenen una o dues), i que l'àngel sosté el

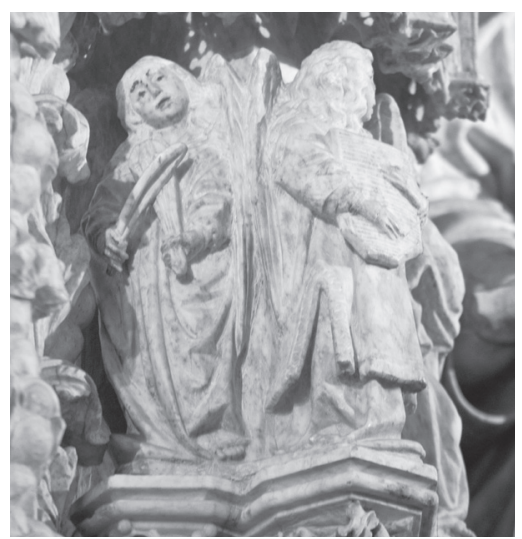

Rabec i saltiri. Retaule de la Verge de la Candelera de Sta. Maria de Castelló d'Empúries (foto. Manel Puig).

4 Hem d'entendre tuba com a sinònim de trompa o trompeta, $\mathrm{o}$ als instruments de la família del vent metall en general. que semblen unes baquetes, una a cada mà. Aquest fet em porta a pensar que es tractaria d'un instrument de corda percudida anomenat tambor de cordes. El fet estrany d'aquesta representació és que, normalment, aquest instrument es percudeix amb una sola baqueta $i$ aquí el trobem representat amb dues. Es tracta d'un instrument més propi de la música popular, i que sovint va acompanyat d'un flabiol. Aquesta conjunció del tambor de cordes amb el flabiol és important en la dansa, ja que permet tocar la melodia i el ritme a la vegada. En aquest cas, però, crec que en lloc del flabiol, el que apareix a la imatge són dues baquetes, perquè cap d'elles és a prop de la boca i per la manera com les agafa l'àngel. Podem destacar que aquest instrument té un cap esculpit a la part superior de la caixa, cosa que no és massa habitual en els tambors de cordes però si en la tromba marina o algun altre instrument de corda fregada.

En el següent grup, al nivell inferior del costat esquerre del conjunt, hi trobem un grup de tres àngels sonadors d'instruments de corda: el rabec, el saltiri i l'arpa.

Durant l'Edat Mitjana, a vegades és difícil classificar els instruments, ja que una mateixa tipologia o família instrumental té moltes variants segons la regió, l'època i fins i tot el repertori per al qual estaven concebuts. En el cas del rabec (instrument de corda fregada), podem distingir-ne dos grans grups: el rabec europeu i el rabec de tradició àrab o rebab.

El primer apareix, aproximadament, entre els S. XII i XIII, i és una barreja entre el rebab àrab i la lyra bizantina. Es tracta d'un cordòfon periforme, format per un bloc de fusta i amb fons bombat. Es toca da braccio, és a dir, recolzat a l'espatlla o al braç.

En canvi, el rabec de tradició àrab (o rebab), procedent del nord del continent africà, és igualment un instrument periforme i de fons bombat, però amb la tapa harmònica dividida en dues meitats; la superior és de fusta i la inferior, de pell. És un instrument que s'acostuma a tocar da gamba, recolzat sobre les cames. 
L'instrument representat en el retaule és un rabec europeu, ja que el músic el toca da braccio. Tampoc es percep que la tapa harmònica estigui dividida en dues meitats.

Woodfield (1999) defensa que a la Corona d'Aragó, el rabec europeu no exerceix cap influència sobre el rabec de tradició àrab fins ben entrat el s. Xv. En canvi, Jordi Ballester (2005) demostra, per mitjà de la iconografia, que la influència europea és anterior al 1450, possiblement des de finals del s. XIV.

A nivell documental, es recull la presència a la cort catalana de músics de rabec d'origen àrab el 1313 i 1337. En canvi, al 1391, el rei Joan I mana comprar «una viola i una rabena qui foren de Gerardin» (Gómez Muntané 1979: doc. 192), un músic d'origen francès que, segurament, tocava un rabec de tradició europea. Segons Jordi Ballester, la transformació d'aquest instrument començarà a finals del XIV, per acabar essent un instrument híbrid.

En el cas de Castelló, ja hem comentat la presència d'un rabec a l'inventari de la casa del temple de 1309. Trobem d'altres exemples, com Bernat Saguer, sonador de rabec de Vilavenut, llogat per tocar en els festejos celebrats a la vila el 16 de novembre de 1405 en honor de la visita del rei Martí (Pujol i Canelles 1990).

El segon instrument és el saltiri, segurament d'origen persa. En el cas del saltiri representat al retaule, i a diferència del que apareix en el protocol notarial, aquest es toca amb els dits. A la representació no s'aprecia cap mena de plectre, mentre sí que veiem les mans obertes sobre l'instrument, fet que impossibilita que aguantés el plectre o els martellets.

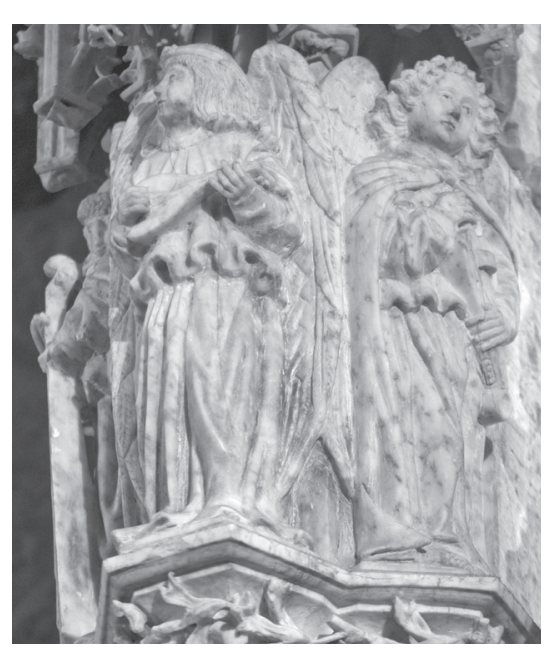

Tromba marina, llaüt i viola de roda. Retaule de la Verge de la Candelera de Sta. Maria de Castelló d'Empúries (foto. Manel Puig). de tecla, quedant gairebé relegat a l'àmbit privat o a l'acompanyament del cant litúrgic, sobretot en convents.

El tercer instrument del grup és l'arpa, un dels instruments més antics. Les primeres iconografies de l'arpa europea daten del s. VIII, i les primeres referències documentals, del s. XIII.

A diferència d'instruments predecessors (com la lira), en el cas de l'arpa medieval, la caixa es recolza sobre el pit i acostuma a ser de dimensions reduïdes. A partir de la segona meitat del segle $x v$ el seu volum augmenta i ja es comença a recolzar a terra. En el cas de la imatge que ens ocupa, l'àngel la sosté encara sobre el pit i és de petites dimensions.

Si passem al costat dret del retaule, podem observar, a la part central, la tromba marina, el llaüt i una viola de roda. Recordem que a la part superior les imatges no s'han conservat.

La tromba (o trompeta) marina, malgrat el seu nom, és un instrument de corda, segurament el successor del monocordi. L'adjectiu «marina» es creu que és una deformació de «mariana». En cas que sigui així, podem relacionar aquest instrument amb el culte, on devia ser utilitzat per reforçar el cant o per fer efectes sonors. D'acord amb aquesta hipòtesi, l'instrument que tenim representat per les seves dimensions estaria destinat a reforçar les veus greus. En aquest cas, sí que podem distingir clarament una mà que sosté l'arc i que frega les cordes, mentre que l'altra pinça la corda per fer les diferents notes.

Seguidament trobem un instrument de corda pinçada. Tot i que per les seves dimensions podria ser una guiterna, jo m'inclino més per un llaüt, degut a la morfologia del claviller en forma de pala. Aquest instrument proba-

Com l'arpa o la vièlle, el saltiri apareix molt relacionat amb les representacions del rei David a l'alta Edat Mitjana. En els segles XIII i XIV té una gran expansió en la música culta però poc a poc anirà essent substituiit pels instruments blement fou introduit des del mon àrab, present en el món cristià ja en els segles XII-XIII, tot i que el període de més rellevància es dóna a partir del s. XVI, moment en el qual és utilitzat, sobretot, en la 
polifonia, en contraposició a la cítola, instrument destinat a acompanyar la monodia. La família dels llaüts acabarà essent molt important en el Renaixement i Barroc. La diferència més important entre el llaüt medieval i els posteriors rau en la manera de tocar-lo. Mentre que al Renaixement les cordes es pincen amb els dits, a l'Edat Mitjana s'utilitza el plectre. Per aquest motiu, el llaüt és sobretot un instrument melòdic, i no harmònic, ja que quan s'abandona l'ús del plectre, l'intèrpret pot reproduir més d'una nota a la vegada i, per tant, fer acords. En el cas de la imatge del retaule, no s'aprecia el plectre, però la posició d'ambdues mans correspon a aquesta tècnica.

El tercer instrument d'aquest conjunt és una viola de roda. Té els seus orígens en l'organistrum, un instrument de grans dimensions que necessita ser sonat per dues persones i que es creu que tenia la funció d'acompanyar el cant pla. Més

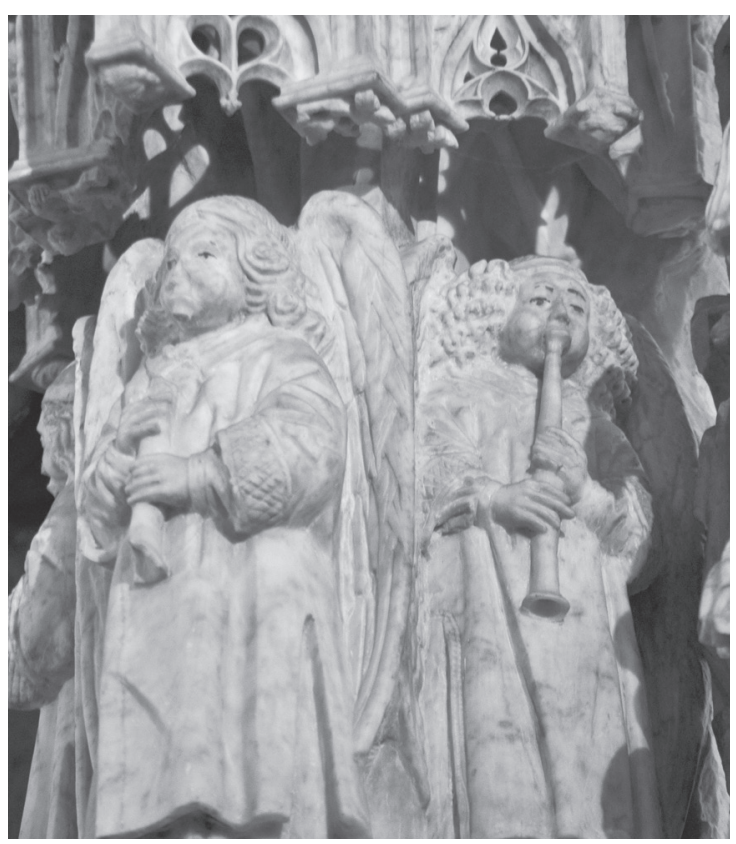

Cornettos. Retaule de la Verge de la Candalera de Sta. Maria de Castelló d'Empúries (foto. Manel Puig).

endavant apareix la symphonia, un instrument ja molt més petit, de forma rectangular i que permet que sigui sonat per un sol intèrpret. Poc a poc deixa de ser un instrument destinat a l'acompanyament del cant litúrgic i queda relegat a la música popular. Malgrat alguns intents de com- pondre música «culta» per viola de roda durant el Barroc, en el s. XVII és considerat un instrument de músics ambulants.

A l'últim grup, en el nivell inferior del costat dret, ens tornem a trobar amb els instruments de vent, en aquest cas vent fusta.

En primer lloc trobem representada una xeremia o flauta de bec. El problema per definir de quin instrument es tracta és que manca la part superior de l'instrument. Precisament correspon a la part de l'embocadura, on trobaríem les característiques que ens permetrien diferenciar de quin instrument es tracta, perquè la flauta de bec és un instrument de bisell i la xeremia de canya doble. Aquesta diferència li atorga una sonoritat molt diferent i, per tant, una funcionalitat musical també diferent.

La xeremia tindria origen asiàtic i probablement hauria estat introduïda pels àrabs al s. $x$. Tot i que inicialment és un instrument relacionat amb la música cerimonial i festiva a l'aire lliure, al s. XIV es comença a estandarditzar una família de xeremies de diferents tessitures, i al s. XV ja forma part de l'anomenada capella alta (instruments de sonoritat potent). Acabarà essent un instrument primordial a les capelles musicals i a les cobles de ministrers de casa nostra. No en va és l'avantpassat del tible i la tenora.

Malgrat que a la figura central d'aquest conjunt també li manca la part superior de l'instrument, em decanto a pensar que els dos instruments que resten són dos cornettos. El cornetto és un instrument de vent format per un tub de fusta cònic amb forats i boquet, semblant al dels instruments de vent metall.

És possible que sigui un instrument més antic però el que sí que sabem del cert és que cap a la fi del s. XV es comença a perfeccionar i jugarà un paper important en la música culta fins a finals del s. XVII, juntament amb la família de les xeremies i del vent metall, que conformaran la plantilla de les cobles de ministrers, molt rellevants per a la vida musical de les nostres contrades.

Si identifiquem aquests dos instruments com a cornettos, marriscaria a dir que el primer és una xeremia, ja que encaixaria en l'orgànic representat en el retaule. 
Aquesta anàlisi dels instruments que apareixen representats en el retaule de la Verge de la Candelera contribueix a reforçar la idea que ja hem apuntat anteriorment pel que fa al caire allegòric de l'escena, allunyada del que devia ser un conjunt de músics real en el s. XV. A la mateixa escena hi trobem representats instruments de la capella alta —instruments que sonen fort-com són els instruments de vent metall (les xeremies i cornettos), juntament amb els instruments de la capella baixa (l'arpa, el rabec, el salteri, el llaüt).

També hi apareixen instruments vinculats a diferents tipus de repertori. El tambor de cordes i la viola de roda, propis del repertori popular, mentre que els anafils ho són de la música representativa; els instruments de vent, propis de la música processional o festiva que s'interpreta a l'exterior, i finalment, els instruments de corda pinçada o fregada, vinculats a la música culta.

Malgrat aquesta barreja, i si observem la disposició dels instruments, podem intuir una voluntat de l'autor per ordenar-los d'acord amb alguna afinitat, sigui de repertori, funció o família. Així doncs, colloca els instruments de vent metall amb els de percussió, els dos grups d'instruments de corda, i finalment, el grup de vent fusta.

Qui sap si amb aquestes representacions d'àngels músics en diferents espais i situacions musicals, l'autor vol transmetre la idea que qualsevol moment, qualsevol celebració és bona per lloar la Verge i el Nen.

Llàstima no poder disposar de les sis imatges que manquen en el retaule. Certament, a la composició s'hi troba a faltar la representació del que ha estat segurament l'instrument central de la vida musical de Castelló al llarg de la seva història, l'orgue, la primera notícia del qual data, segons Miquel Pujol (1990), de l'any 1420.

Ara ja només manca que es dugui a terme un projecte de reconstrucció similar al que s'està fent a Ripoll durant la redacció d'aquestes línies. Dirigit per Antoni Madueño, s'estan reconstruint els instruments de la Portalada de Ripoll. Prenent el nom del seu projecte, despertem nosaltres també els nostres instruments adormits.

\section{Bibliografia citada}

Álvarez Martínez, Rosario, 2007: «Incidencia de una forma de trabajo en la representación de los instrumentos musicales: la copia de códices en la Edad Media». Nassarre: Revista aragonesa de musicología, 23 . 1, 53-70.

BALLESTER, Jordi, 1993a: «lconografia musical en la pintura gòtica catalanoaragonesa», Revista de musicologia, vol. Xvı, n. 6, 3236-3277.

BALLESTER, Jordi, 1993b: «Representacions musicals en la pintura catalana del s. XVI», Revista catalana de musicologia de musicologia, n. 2, 53-61.

BALLESTER, Jordi, 2005: «lnfluencias del Rebec europeo sobre el Rabel Hispánico a finales de la edad media en la corona de Aragón», Anuario Musical, 6o, 21-26.

GIRONeLLA, Josep Maria, 2013: «200 anys d'art i poder a la cort dels
Empúries, conferència-concert amb el conjunt de música medieval Locus Desperatus», XXIII Festival Terra de Trobadors.

Pujol I Canelles, Miquel, 1990: «La música i el cant durant els segles XIV al XVII a Castelló d'Empúries», Catàleg de l'exposició Castelló d'Empúries i la música. Ajuntament de Castelló: 5-14.

Pujol I Canelles, Miquel, 1984: «Els Templers a l'Empordà. La Comanda del Temple de Castelló d'Empúries», Annals de l'Institut d'Estudis Empordanesos, 17, 33-94.

Pujol I Canelles, Miquel, 1989: «El retaule d'alabastre de Santa Maria de Castelló d'Empúries», Annals de l'Institut d'Estudis Empordanesos, 22, 69-96.

lan Woodfield, 1999: La viola da gamba, dalle origini al Rinascimento, Renato Meucci, Torino: EDT.

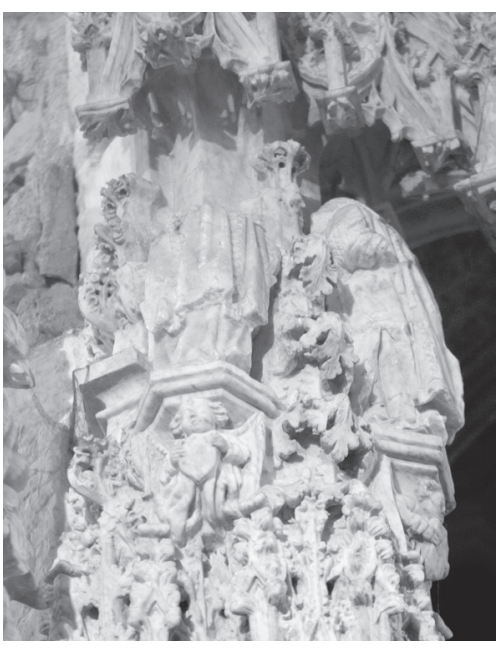

Imatges destruïdes. Retaule de la Verge de la Candalera de Sta. Maria de Castelló d'Empúries (foto. Manel Puig). 